\title{
O TEMPO DO PROCESSO E O PROCESSO ELETRÔNICO
}

Paulo Roberto Pegoraro Junior

Doutorando em Direito pela PUC/RS. Mestre em Direito pela UNIPAR. Professor da Faculdade de Ciências Sociais Aplicadas de Cascavel (UNIVEL). Advogado.

Avenida Brasil, 6282, Ed. Central Park, $8^{\circ}$ andar, Centro, CEP 85.810-000, Cascavel/PR, telefone (45) 3304-4848, e-mail paulopegorarojr@hotmail.com

José Maria TeSheINER

Professor-Orientador no Programa de Pós-Graduação em Direito da PUC/RS. Desembargador aposentado do TJ/RS. Livre-docente e Doutor em Direito pela Faculdade de Direito da Universidade Federal do Rio Grande do Sul - FURG.

Avenida Ipiranga, 6681, Prédio 11, $10^{\circ}$ andar, Partenon, CEP 90.619-900, Porto Alegre/RS, telefone (51) 3222-0986, e-mail josetesheiner@gmail.com

\section{Resumo}

O papel cada vez mais destacado que assume o processo eletrônico como meio técnico de prestaçáo jurisdicional deve ser compreendido a partir da dimensáo relacionada ao tempo do processo e das suas formas de atuação. A partir da análise das linhas temporais do processo, é possível entender o quanto os postulados da celeridade e da efetividade são ou não atingidos pela virtualização dos atos processuais, em especial levando-se em conta as inovaçôes do projeto do novo Código de Processo Civil. A par disso, nấo se pode ignorar o viés econômico imposto pela compressão temporal e pelas exigências da instantaneidade da prestação jurisdicional, afetando de modo significativo o tempo qualitativo do processo.

\section{Palavras-chave}

Processo eletrônico; Tempo do processo; Prestaçáo jurisdicional; Código de Processo Civil.

\section{Abstract}

The increasingly important role of the electronic process as technical means of adjudication must be understood from the dimension related to the process time and its forms of action. From the analysis of the process steps, we can understand how the principles of the speed and effectiveness are or not affected by the virtualization of procedural acts, 
especially taking into account the innovations of the draft of the new Civil Procedure Code. Apart from this, one cannot ignore the economic bias imposed by temporal compression and by the demands of immediacy of adjudication, significantly affecting the quality of the process time.

\section{Key words}

Electronic process; Processing time; Adjudication; Code of Civil Procedure.

\section{Introdução}

A demanda por celeridade e efetividade da prestação jurisdicional tem sido a tônica do discurso acerca da atuação do Poder Judiciário ao longo dos últimos anos, não somente no Brasil mas em diversos outros países, impulsionada pela angústia da instantaneidade oferecida pela Internet, como aponta David Harvey (2013, p. 257) acerca da "compressão do espaço-tempo" intensificado nas últimas duas décadas, impactando desorientada e disruptivamente as práticas político-econômicas, o equilíbrio do poder de classe, bem como a vida social, cultural e jurídica. Não por outra razão Egas Dirceu Moniz de Aragão dizia que "entre dois ideais, o de rapidez e o de certeza, oscila o processo" (ARAGÃO, 1976, p. 100).

$\mathrm{Na}$ sociedade pré-industrial, identificada com o setor primário da economia, a cadência do tempo era marcada por contingências naturais, como as estaçóes do ano, o tipo de solo, a quantidade de chuvas, etc. Por isso, "a sensação do tempo é a da durée, o de momentos longos e breves, e o ritmo do trabalho varia com as estaçóes e com as intempéries" (BELL, 1977, p. 146). Mas a sociedade de massa já não se contenta com um Poder Judiciário artesanal, pois é marcada pela otimização dos recursos, pela produção industrial, o que nos conduziu às tutelas coletivas, à sumula vinculante e à impeditiva de recursos, enfim, ao processo civil de massa.

Mas o processo civil de massa náo é suficiente para dar conta dos anseios pela prestação jurisdicional. Segundo David Harvey (1977, p. 147), quanto ao tempo, a contemporaneidade é marcada por uma constante aceleração do ritmo dos processos econômicos e da vida social; quanto ao espaço, por uma redução das barreiras espaciais com vistas à consagraçáo do mercado mundial (o conceito de aldeia global), tendo por resultado um acentuado incremento da velocidade das expectativas (frustradas ou não) e na resposta esperada. Já em 1945 Eduardo Couture dizia que "en el processo el tiempo es algo más que oro: es justicia” (1945, p. 37).

$\mathrm{O}$ culto à velocidade (dromolatria) apresenta-se de forma insaciável na sociedade pós-moderna, de modo que a economia, movida pela racionalidade técnica, exige da 
política e do direito, movidos pela racionalidade prática, uma aceleração dos processos decisórios, que acompanhe sua própria aceleração (BECKER, 2012, p.342), requerendo um tratamento adequado aos meios técnicos utilizados: o eletrônico, o digital. Luiz Guilherme Marinoni observa que "se o tempo é a dimensão fundamental da vida humana e se o bem perseguido no processo interfere na felicidade do litigante que o reivindica, é certo que a demora no processo gera, no mínimo, infelicidade pessoal e angústia e reduz as expectativas de uma vida mais feliz (ou menos infeliz)" (MARINONI, 2000, p. 17).

No Brasil, a exigência vem acompanhada de perto pela atuação do Conselho Nacional de Justiça - CNJ, ao produzir levantamentos detalhados da produtividade de magistrados (Relatório Justiça em Números) e a impor ao Judiciário a adoção e execução de metas anuais, tais como a de julgar, até 31/12/2015, 80\% dos processos distribuídos até 31/12/2011 no 1o grau da Justiça Estadual (CNJ, 2015).

Mas a urgência que embala o processo, além de cumprir as exigências constitucionais e legais de que a prestaçáo jurisdicional seja entregue em prazo razoável, atende, mais profundamente, a uma lógica ditada pelo modelo econômico e sua modelagem, a tecnologia de informação e comunicação (SALDANHA, 2015, p. 190), como resultado de uma nova economia e um novo modo de governar, regido pela matriz neoliberal da concorrência. O ideário da padronização é uma clara resposta ao modelo econômico, "cujo núcleo duro é representado por modelos de gestão, pela quantificação e pelo fluxo" (SALDANHA, 2015, p. 196), tratando-se de um comprometimento muito mais político do que propriamente jurídico.

A tecnologia tem servido para oferecer um novo meio para a prestação jurisdicional, o processo eletrônico, ainda que padeça de muitas das vicissitudes e limitaçóes do "antigo" processo físico. No mais das vezes, seja pela condição experimental, seja pela ausência de unificação plena do sistema, entre os tribunais pátrios, o que o processo dito eletrônico tem oferecido apenas a virtualização (ou digitalização) dos atos que eram até então praticados em papel. O que se quer dizer é que ainda não se concebeu, em nosso país, um modelo de prestação jurisdicional efetivamente eletrônico, mas sim apenas o transplante de um modelo físico para virtual.

A despeito desse quadro incipiente, é possível apontar algumas conseqüências da adoção do novo modelo, especialmente com relação ao tempo do processo, pois há uma relação inegavelmente diferenciada em relação a prática processual de uma década atrás. Esse é o objetivo do presente artigo.

\section{0 Modelo de Informatização do Processo Judicial Brasileiro}

A despeito da escolha da denominação de "processo eletrônico" pela Lei no 11.419/2006, que regulamentou seu uso, tecnicamente soa adequado abordar o tema a 
partir da compreensão da informatização do processo judicial, tal como o fez a própria lei em seu preâmbulo, muito embora a noção de processo sem papel tenha surgido antes da apontada norma.

Conforme Rover (2008), processo digital é resultado da informatização de um conjunto mínimo e significativo de açóes e, por consequência, de documentos organizados e ordenados em uma sequência definida de fluxos de trabalho - representando fases processuais, atendendo a requisitos de autenticidade, temporalidade e integridade, com a eliminação do uso do papel.

O fenômeno está ligado ao conceito internacional de Justiça Eletrônica, que já tem registrado destacada evolução nos vários sistemas de justiça na última década (ZAMUR FILHO, 2011), e que e impóe em virtude das possibilidades de comunicação e de acesso aos sistemas informáticos dos tribunais por meio da Internet, com alcance mais amplo que as regras observadas na informatização e comunicação dos atos processuais.

A denominação da aplicação da tecnologia da informação nos tribunais, internacionalmente convencionada como "e-justice", merece também ressalvas, por se dever ditinguir conteúdo e continente: o processo judicial eletrônico é a principal finalidade das facilidades e funcionalidades oferecidas, e a informatização e a telemática até aqui aplicada pelos tribunais têm por objetivo a prestação jurisdicional e dela decorrem; por Justiça Eletrônica, contudo, deve ser considerada "mais uma daquelas expressôes hiperbólicas utilizadas para se dar ênfase aos discursos sobre a modernização da Justiça pelo uso intensivo da tecnologia" (ZAMUR FILHO, 2011, p. 14-15).

A transformação da lógica processual em curso leva em conta alguns elementos identificáveis: a interatividade, a desmaterialização, a instantaneidade e a desterritorialização possibilitada pela Internet e por outros meios telemáticos. Segundo André Andrade (2010), houve embate entre a corrente idealista e pragmática no desenho da informatização do processo judicial, representando, respectivamente, interesses dos juízes (AJUFE) e dos advogados $(\mathrm{OAB})$. Da tal disputa teria resultado o veto presidencial à compulsoriedade de cadastro junto aos tribunais (art. 17) e redação confusa nas alterações do Código de Processo Civil.

O prestígio do processo eletrônico como meio técnico da prestação jurisdicional pode ser aferido pelo massivo investimento do Poder Judiciário nessa tecnologia, que registrou crescimento de 33,9\% entre 2011 e 2012, superior em muito a todas as demais rubricas, muito embora a variação do investimento total no ano seguinte, entre 2012 e 2013, tenha tido decréscimo de 1,8\%, alcançando a soma de R $\$ 2$ bilhóes e 723 milhóes de reais em todo o Judiciário, com exceção dos gastos com o Supremo Tribunal Federal e os Conselhos (vide Relatório Justiça em Números 2013, p. 298, e Relatório Justiça em Números 2014, p. 38). A tecnologia da informação e a celeridade, desta forma, acabam 
sendo articuladas de meio para fins, tornando mais difícil que se encontrem outras soluçóes para o quadro de crise do Judiciário, tal como a qualidade das decisóes judiciais, relacionada à formação dos juristas e sua compreensão do $\bigotimes$ Direito.

O novo Código de Processo Civil (Lei no $13.105 / 2015$ ) contempla uma seção própria para a prática eletrônica de atos processuais (arts. 193/199), permitindo a produção, comunicação, armazenamento e validação dos atos processuais por meio eletrônico, assegurando as garantias da "disponibilidade, independência da plataforma computacional, acessibilidade e interoperabilidade dos sistemas, serviços, dados e informaçóes que o Poder Judiciário administre no exercício de suas funções” (art. 194).

$\mathrm{O}$ novo $\mathrm{CPC}$ exige que o registro do ato processual eletrônico se dê em padrão aberto, que atenda aos requisitos de autenticidade, integridade, temporalidade, não repúdio, conservaçáo e, nos casos que tramitem em segredo de justiça, confidencialidade, observada a infraestrutura de chaves públicas unificada nacionalmente, competindo ao Conselho Nacional de Justiça e, supletivamente, aos tribunais, regulamentar a prática e a comunicação oficial de atos processuais por meio eletrônico e velar pela compatibilidade dos sistemas, disciplinando a incorporação progressiva de novos avanços tecnológicos.

O que não se pode ignorar diante de todo o processo de digitalização e informatização do Judiciário é que toda a opção e todos os "dispositivos e sistemas exibem tendências morais" (BAUMAN, 2014, p. 91), de modo que é absolutamente compreensível que o mundo virtual atenda aos postulados do neoliberalismo ditados pela urgência, instantaneidade, produtividade e fluxo de dados: "Afinal, se a mediação eletrônica facilita as relações humanas e a atuação das instituiçôes, seguramente ela não é neutra e sua 'direção moral' não é revelada apenas no tocante à finalidade para a qual é utilizada. Os pensadores da segunda tradição da sociologia, no início do Século XX, já se preocupavam com o 'impacto da tecnologia e da ciência sobre a sociedade' porque naquela época as consideravam 'forças estranhas', lembrou Giddens. Como refere David Lyon, 'Todo desenvolvimento tecnológico certamente é produto de relações culturais, sociais e políticas' (SALDANHA, 2015, p. 203).

\section{As Linhas Temporais do Processo}

O tempo do processo em sentido amplo pode ser decomposto em pelo menos três linhas paralelas: uma constante e duas variáveis, na definição de Becker (2012, p. 343). A constante é a temporalidade ordinária, lapso que abrange o tempo de cada coisa em movimento e consiste na duração que encerra o espaço, também denominada de duração homogênea (CRUZ E TUCCI, 1997). Daí porque a noção de que "tiempo y movimiento están vinculadas entre sí tan estrechamente que son interdefinibles: medimos el tiempo por el movimiento, pero también el movimiento por el tiempo" (MORA, 1986, p. 409). 
A constante da temporalidade ordinária, o tempo marcado, pode ser claramente ilustrado com a adoção do relógio atômico pelo Supremo Tribunal Federal, em 2007, para marcar o tempo da Justiça em todo o país (STF, 2015), mantendo o rigorismo do horário com equipamento baseado no elemento rubídio, a conferir a precisáo do tempo universal em bilionésimos de segundo.

A primeira das variáveis envolvidas no tempo do processo em sentido amplo é o tempo do processo em sentido estrito, medido pela extensão dos prazos processuais, bem como pelo número de fases processuais, de audiências e recursos possíveis. A atuação em tal variável no sentido de conferir celeridade e efetividade envolve sobretudo as tentativas de simplificação ou, por vezes, a sumarização do processo (vide Juizados Especiais, procedimento sumário, procedimento do mandado de segurança, entre outros). A eventual “complicação procedimental” (CARNELUTTI, 1939, p. 9) implica o aumento dessa variável, como acontece na ação de reintegração de posse com o acréscimo de audiência de justificação prévia (art. 928 do Código de Processo Civil).

A dimensão da sumarização formal do processo não se confunde com a limitação da cognição no plano vertical (cognição sumária), identificada com as tutelas de urgência (antecipação de tutela e cautelares), porque, no primeiro caso, há supressão de matéria cognoscível e, no segundo, mero diferimento de ato processual, o que se verifica em especial nas decisóes sem a oitiva da parte contrária previamente ("inaudita altera parte”). Por outro lado, o uso da cognição sumária representa uma redistribuição eficaz de ônus processual, pois exige a prova pré-constituída (requisito da prova inequívoca da verossimilhança, na antecipação de tutela, e do fumus boni iuris, nas cautelares), otimizando o uso do expediente pelas partes e contribuindo, ainda que indiretamente, com o tempo do processo em sentido amplo.

Daí a crítica de Luiz Guilherme Marinoni (1995) no sentido de que a franca adoção, pelo modelo processual brasileiro, do procedimento ordinário do processo civil como técnica universal de solução de litígios, deve ser substituído por outras estruturas procedimentais, mais condizentes com a espécie de direito material a ser tutelado: "O procedimento ordinário, como é intuitivo, faz com que o ônus do tempo do processo recaia unicamente sobre o autor, como se este fosse o culpado pela demora ínsita à cognição dos direitos. Tal construção doutrinária é completamente alheia ao que ocorre na realidade social e no plano do direito substancial, pois neste plano há direitos evidentes e não evidentes e na realidade da vida a lentidão do processo pode significar angústia, sofrimento psicológico, prejuízos econômicos e até mesmo miséria. É preciso, assim, que ao tempo do processo seja dado o seu devido valor, já que, no seu escopo básico de tutela dos direitos, o processo será mais efetivo, ou terá uma maior capacidade de eliminar com justiça das situaçóes do conflito, quando mais prontamente tutelar o direito do autor que tem razão. De nada adianta a doutrina continuar afirmando, retoricamente, que a justiça atrasa é 
uma injustiça, se ela não tem a mínima sensibilidade para perceber que o processo sempre beneficia o réu que não tem razão" (MARINONI, 1995, p. 17).

Elaine Harzheim Macedo (1997) também logrou identificar o "reinado quase que absoluto da ordinarização do processo", arraigado no sistema de rígida separação de poderes do Estado, ainda que não tenha implicado a renúncia às formas procedimentais que atende à dinâmica da substancialização da prestação jurisdicional, afastado do arquétipo do procedimento ordinário e da cognição plena.

O atual modelo de procedimento ordinário, que é modular, admitindo antecipaçáo de tutela, já tem certo grau de flexibilidade, para ajustamento às necessidades do caso concreto. Sendo o fator tempo um elemento determinante para garantir a efetividade da prestação jurisdicional, e que a técnica da cognição sumária pode ser compreendida a partir da redução do tempo do processo em sentido estrito (TPSE), delineia-se a ideia de um processo que espelhe a realidade sócio-jurídica a que se destina, "cumprindo sua primordial vocação que é a de servir de instrumento à efetiva realização dos direitos" (WATANABE, 1987, p. 110).

O Código de Processo Civil de 1973 dedica dois capítulos à questão temporal: um, denominado "Do Tempo e do Lugar dos Atos Processuais Civis" e outro intitulado "Dos prazos”. O primeiro arrola as regras relativas aos horários e dias em que são realizados os atos processuais, e as férias e feriados forenses. Neste, há regras sobre o modo de cômputo dos prazos, as causas de suspensão do seu curso, as penalidades em caso de descumprimento, os prazos a serem observados por juízes e serventuários, além de outras normas gerais.

Da análise dessas normas, constata-se uma preocupação significativa do legislador com o fator temporal do processo (DUARTE, 2009, p. 38). Veja-se que os artigos 189 e 190 determinam que o juiz deve proferir despachos em 2 dias e decisóes em 10 dias, e que o serventuário deve remeter os autos conclusos em 24 horas e executar os atos processuais em 48 horas, sob pena de instauração de procedimento administrativo disciplinar (arts. 193, 194, 198 e 199). Por sua vez, o artigo 35, inciso II, da Lei Orgânica da Magistratura Nacional dispóe que, entre os deveres do magistrado, está o de "não exceder injustificadamente os prazos para sentenciar ou despachar". E o artigo 39 dessa lei prevê que os juízes devem remeter mensalmente ao órgão corregedor de segundo grau informação sobre os feitos cujos prazos para despacho ou decisão hajam sido excedidos.

Ainda no plano do tempo do processo em sentido estrito, é possível identificar algumas inovaçóes do novo Código de Processo Civil (Lei no 13.105/2015), a destacar: o afastamento da regra de preclusão no tocante às decisóes interlocutórias (art. 1.009, p. 1o); o exercício do juízo de admissibilidade do recurso especial e do recurso extraordinário diretamente pelo Superior Tribunal de Justiça ou pelo Supremo Tribunal Federal, 
respectivamente, sem a necessidade de admissão pelo tribunal local (art. 1.030, p. ún.); a estabilização da tutela de urgência na hipótese de parte contrária não interpor recurso (art. 304); a dispensa da propositura de nova ação para o caso de tutela antecipada requerida em caráter antecedente (art. 303, p. 1º inc. I), bastando o mero aditamento da inicial. Por outro lado, andou mal ao manter a regra de que o recurso de apelação é recebido no efeito suspensivo (art. 1.012), deixado de lado uma oportunidade histórica para o resgate da importância e da efetividade da sentença de primeiro grau.

A segunda variável envolvida no tempo do processo é o tempo do meio técnico do processo, que envolve o tempo da juntada de petiçóes, da conclusão para decisão, da expedição de mandados, da comunicação de atos processuais para ciência das partes (BECKER, 2012, p. 345), que é efetivamente influenciado pela alteração do próprio meio utilizado e que está no foco da demanda pela produção digital e pelo processo eletrônico. A aceleração do tempo do meio técnico do processo influencia diretamente o tempo do processo em sentido amplo, como apontou estudo realizado por Maurício José Ribeiro Rotta et al, no qual se constatou que a implantação do processo judicial digital pode aumentar "de 200\% a 400\% a aceleração do tempo de tramitação dos processos, desde a distribuição, até o trânsito em julgado da sentença" (ROTTA, 2013, p. 150). Esta aceleração está associada à redução do "tempo morto" do processo, presente em algumas fases na tramitação dos autos, até que se alcance o transito em julgado da sentença.

Em 2007, estudo da Secretaria de Reforma do Judiciário do Ministério da Justiça que analisou a rotina de quatro cartórios do Estado de São Paulo, descobriu que os atos que mais consomem tempo no processo são as publicaçôes, que utilizam entre $51,4 \%$ e $69,3 \%$ do tempo total do processo em cartório, e as juntadas, que demandam entre $7 \%$ e $38,8 \%$ desse mesmo tempo. Outro dado impressionante diz respeito ao tempo em que o processo permanece em cartório, mesmo depois de proferida a sentença: em média 278,6 dias (DUARTE, 2009, p. 97), evidenciando que o tempo de inatividade processual acaba sendo maior do que o tempo de atividade, em que são efetivamente praticados os atos necessários ao seu desenvolvimento. Daí o destaque de Giuseppe Tarzia: "Os problemas mais graves da Justiça civil, pelo menos na Itália, dizem respeito, de outra parte, não à estrutura, mas à duração do processo; dizem respeito aos tempos de espera, aos 'tempos mortos', muito mais que aos tempos de desenvolvimento efetivo do juízo. A sua solução depende, portanto, em grande parte, da organização das estruturas judiciárias e não das normas do Código de Processo Civil” (TARZIA, 1995, p. 89).

Daí que a grande aposta do processo eletrônico esteja na eliminação das etapas mortas do processo, que permite a efetiva eliminação ou redução das fases de inatividade, como já antevia Athos Gusmáo Carneiro: "As maiores demoras no andamento dos processos judiciais, como bem sabem os operadores do Direito, não ocorrem em consequência da sucessão de recursos, ou de eventuais manobras protelatórias das partes, ou da necessidade de audiências com seus frequentes adiamentos. As maiores demoras são as 
decorrentes dos 'dias mortos', em que os processos aguardam, em pilhas e pilhas, as providências cartorárias para a publicação das notas de expediente, para a juntada de petiçóes, para a expedição de mandados, para a efetiva 'conclusão' dos autos aos juízes. Neste passo, esperemos que a ampla informatização dos processos, com a permissáo para a prática e comunicaçáo dos atos processuais por via eletrônica (Lei n. 11.280, de 16.2.2006, que acrescentou um parágrafo único ao art. 154 do CPC) em muito venha a contribuir para a celeridade desejável" (CARNEIRO, 2007, p. 6).

Prova disso é que, em maio de 2009, o Tribunal Regional do Trabalho da 13a Região noticiou que a Vara do Trabalho de Santa Rita/PB, que era a primeira eletrônica do Brasil e que completava um ano de funcionamento, havia reduzido em 36 dias (de 48 para 12) o prazo médio desde a distribuição da ação até a primeira audiência, e que o prazo de conclusão para despacho, que era de três a cinco dias, havia sido reduzido para 24 horas (TRT13, 2009).

A alteração do meio técnico do processo também pode repercutir no tempo do processo em sentido estrito ao se afastar a necessidade do prazo em dobro para litisconsortes com procuradores diferentes (art. 191 do CPC), na dispensa da interrupção do julgamento colegiado por sucessivos pedidos de vista, da supressão em geral dos prazos sucessivos com sua conversão para prazos comuns, diante da disponibilidade virtual do processo. A tal respeito, o novo Código de Processo Civil prevê a ordem cronológica de conclusão para que seja proferida a sentença ou acórdão (art. 12), a juntada automática de petiçóes ou manifestaçóes, nos processos eletrônicos, independente de ato de serventuário (art. 228, p. 2o), o fim da regra do prazo em dobro para litisconsortes com procuradores distintos, no caso de processos eletrônicos (art. 229, p. $2^{\circ}$ ), a possibilidade de que a audiência de conciliação ou mediação seja realizada por meio eletrônico (art. 334, p. $7^{\circ}$ ) e a realização eletrônica de julgamentos colegiados nos processos de competência originária que não admitam sustentação oral (art. 945).

Como se percebe, o tempo do meio técnico do processo é efetivamente influenciado pela adoção do processo eletrônico, atendendo a demanda pela prestação jurisdicional e implicando a digitalização: a) da produção, reprodução e distribuição; b) de comunicação dos atos; c) de execuçáo; e d) de arquivamento e pesquisa de atos processuais. Do mesmo modo, soa perceptível que o ganho de produtividade no tocante ao tempo do processo eletrônico não se verifica em relação à outra variável (o tempo do processo em sentido estrito), eis que a atuação desta se dá sobretudo por meio de alteraçóes legislativas, no tocante aos ritos, em especial, e os atos processuais considerados em sentido lato.

\section{4. $\mathbf{O}$ Culto à Velocidade e o Risco da Alienação: Cronos Versus Kairos}

A economia, que é regida pela racionalidade técnica, costuma cobrar da política e do direito, que são movidos pela racionalidade prática, uma clara aceleração dos processos 
decisórios (BECKER, 2012, p. 342), que acompanhe sua própria aceleração, requerendo para tanto um tratamento que considera adequado aos meios técnicos utilizados: o digital. É um sintoma de uma sociedade guiada pelo culto a velocidade (a dromolatria dos autores italianos), que pode implicar numa solução míope para os problemas da prestação jurisdicional, ao se problematizar a demora e a inefetividade do processo de modo unidimensional, esquecendo-se dos aspectos administrativos, políticos, econômicos e, sobretudo, éticos.

Há um sério risco envolvido na simplificação do problema (ou da solução) a partir da virtualização, que pode contribuir tanto para a manutenção do distanciamento do Judiciário da sociedade como, também, em nome do culto da urgência e da aceleração, "o mais potente antídoto contra a morosidade, as garantias processuais, como a do devido processo legal, do contraditório, da ampla defesa, e sobretudo, a da fundamentação" (SALDANHA, 2015, p. 202), que podem estar sendo ofuscadas ou violadas. A transformação do processo, como garantia constitucional contra qualquer tipo de violação de direitos, não pode se traduzir apenas em mecanismo formal de acesso à justiça. Um caminho reflexivo sobre o impacto das novas tecnologias pode ser extraído da seguinte passagem de Ovídio Baptista da Silva: "Quando os positivistas imaginam que o ato de julgar pressupóe que o juiz se possa despir de seus valores, de sua imersão na comunidade cultural que o produziu, tornando-se um autômato, provavelmente preparado para a justiça cibernética, produzida em série, cometem um grande equívoco e prestam homenagem ao racionalismo cartesiano" (BAPTISTA DA SILVA, 2009, p. 94).

A virtualização e informatização do processo pode ser analisada a partir da perspectiva do novo formato de justiça, oferecida pelo processo eletrônico, que implica a clara modificação da fisionomia do processo e transforma a prestação jurisdicional em um serviço, cujo valor essencial é a eficiência. A assimilação da lei ao preço jurídico, como refere Garapon, é tudo o que quer o modelo liberal, que espera um sentido claro de todas as regras e "faz pouco caso dos problemas de interpretação" (GARAPON, 2010, p. 47). Um claro sintoma dessa lógica é a compressão do tempo presente, que traz como consequência importante a "destemporalização da justiça".

Os gregos utilizavam duas palavras distintas para se referir ao tempo: cronos e kairos. Cronos referia-se ao tempo quantitativo, ou seja, o tempo que pode ser medido, enquanto que kairos se referia ao tempo em seu aspecto qualitativo, a um momento decisivo, a uma ocasião oportuna:

O tempo de kairos pressupóe a existência do tempo de cronos, náo se tratando de concepçôes do tempo dissociadas completamente entre si. A adequação e a oportunidade do momento para realização de uma tarefa ou para a resolução de um problema surgirá em determinado dia e hora (kairos), que podem ser quantificados pelo tempo de cronos. O tempo de cronos também depende de kairos para explicar de forma satisfatória 
a existência humana, uma vez que aquele, sozinho, não consegue explicar o surgimento de ocasióes especiais e decisivas, inclusive em relação a eventos históricos, por lhe faltar atributos qualitativos. Para compreender a história, mesmo de pequenos acontecimentos, é preciso recorrer a datas (cronos), mas também é necessário destacar os acontecimentos mais importantes (kairos).

Para Andre Vasconcelos Roque e Francisco Carlos Duarte, "a mitologia grega contém alguns relatos esporádicos, que remetem às palavras cronos e kairos. $\mathrm{Na}$ teogonia órfica, Chronos é retratado como a própria personificação do tempo, um deus primordial, formado por si mesmo, que conduzia o ritmo dos céus e o caminhar eterno do tempo. Chronos é frequentemente confundido com o titã Cronos da teogonia clássica de Hesíodo, divindade suprema da segunda geração de deuses da mitologia grega. Cronos é filho de Urano, o Céu estrelado, e Gaia, a Terra, tornando-se senhor do céu após castrar seu próprio pai com um golpe de foice. Cronos casou-se com sua irmã Reia e tiveram seis filhos: três mulheres (Héstia, Deméter e Hera) e três homens (Hades, Poseidon e Zeus). Como tinha medo de ser destronado por um de seus filhos, Cronos os engolia assim que eles nasciam. Entretanto, Zeus acabou sendo salvo de seu destino por Reia, que conseguiu enganar Cronos enrolando uma pedra em um pano, a qual ele engoliu sem perceber a troca. Quando Zeus cresceu, resolveu então vingar-se de seu pai. Uma poção mágica fez Cronos vomitar todos os filhos que havia devorado no passado. Zeus tornou-se senhor do céu e divindade suprema do Olimpo, afastando o pai do trono. Poseidon tornou-se o senhor dos mares e Hades assumiu o mundo dos mortos" (ROQUE; DUARTE, 2013, p. 303).

A representação de Kairós na mitologia grega, embora escassa, identifica um deus de baixa estatura, jovem homem nu, de asas nos ombros e nos tornozelos, que corre num movimento de fuga segurando uma lança. O caráter furtivo e veloz é representado pelas asas, aludindo ao tempo que não passa, mas voa. Sua cabeça, calva, contendo uma única mecha, representando a oportunidade. "Se alguém não for capaz de segurar a oportunidade no momento em que ela surgir, depois que ela passar isto não mais será possível, pois as mãos escorregarão pela calvície de Kairós, não podendo ser puxado de volta” (ROQUE; DUARTE, 2013, p. 303).

O processo eletrônico representa clara opção jurisdicional pelo tempo quantitativo (cronos), em desprestígio do tempo qualitativo (kairos), tal como se dá com a própria sociedade contemporânea, que sucumbiu à impiedosa devoração de minutos, horas e dias, quiçá movida pela busca da redução dos custos de transação ante a pendência de um estado de incerteza enquanto náo se decide o conflito de interesses posto em juízo.

É claro que a análise qualitativa do tempo do processo não pode deixar de considerar as chamadas "etapas mortas" do processo, em que não há atividade processual por fatores estruturais da administraçáo da Justiça, a que o processo eletrônico tende eficazmente combater (como já vimos no tocante à juntada automática de petiçóes, a comunicação 
dos atos processuais, entre outras). A expressão foi cunhada por Alcalá-Zamora para designar períodos de "inactividade procesal, durante las que los autos o expedientes se empolvan en las estanterias judiciales” (ALCALÁ-ZAMORA Y CASTILLO, 1974, p. 21). Para o mestre espanhol, são elas, "y no los plazos previstos en ley (...) cuya suma representa bien poco (semanas o meses cuando más) em la vida total de um processo, las que hacen interminables los litígios y, por tanto, las que hay que combatir com máxima energia" (idem, ibidem).

Mas a dimensão quantitativa, inexorável que é (e que envolve uma constante quando se analisa o tempo do processo), não pode desprezar o aspecto qualitativo, não apenas quando se refere a técnicas de gerenciamento de processos ("case management"), mas também decorrente das mais variadas formas de "estandartização" do conteúdo decisório da demanda, da produçáo de sentenças em série, passando-se de uma "certeza" iluminista à previsibilidade e à eficiência, travestidas pelos critérios da rapidez e da quantificaçáo (SALDANHA, 2015, p. 191): "A dificuldade em romper com a barreira da certeza e da segurança, imposta pelo ideário da padronização, está em que ela responde à demanda do modelo econômico neoliberal de governar, cujo núcleo duro é representado por modelos de gestão, pela quantificação e pelo fluxo. Na verdade, trata-se, como já dissera Ovídio de um comprometimento muito mais político do que jurídico, na medida em que manter a segurança e a certeza, de um lado, e o método da estandartização, de outro, imprescinde de um novo modelo de homem - o homem consumidor. Como refere Bauman, no mundo contemporâneo, 'ninguém pode se tornar o sujeito sem primeiro virar mercadoria...'. Trata-se de uma nova configuraçáo humana, a do consumidor-mercadoria ou a do homo consumericus de que fala Lipovetsky" (SALDANHA, 2015, p. 196).

A padronizaçáo das decisóes judiciais, que se apresenta como consequência necessária da pós-modernidade e da sociedade de massas, será sem dúvida, para o bem e para o mal, potencializada pelo processo eletrônico. A utilizaçáo de programas de inteligência artificial que ajudam o usuário a elaborar raciocínios e a tomar decisôes ("Expert Systems" ou "Decision Support System") ilustra bem os caminhos que a sofisticação da utilização da informática pode propiciar e que são capazes de simular aquela parte do raciocínio jurídico que das normas extrai conclusôes (excluída a interpretaçáo) ou dos precedentes consegue extrair uma regra (“Cognitive Mapping Systems"): "No Japão, entre 1966 e 1968, desenvolveram-se projetos para automatizar a partilha de cotas hereditárias e para verificar a legalidade de pedidos de patentes. Em diversos países, como na Inglaterra, na Espanha, na Noruega e na Alemanha, têm sido desenvolvidos sistemas para solucionar questôes fiscais, decidir pedidos de divórcio, resolver litígios contratuais e aplicar a legislação penal de trânsito. Guibourg, Olende e Campanella noticiam que a chamada Informática de Gestão Judicial tem sido empregada com sucesso em vários países, inclusive no Brasil, como se observa dos seguintes exemplos: litígios de acidentes do trabalho, em Mogi das Cruzes 
(1973); tribunal municipal de faltas em Buenos Aires (1960); execuçóes hipotecárias e pignoratícias na província de San Juan (1980); em Barcelona, nos litígios trabalhistas. O SAL - Sistema de Administração Laboral, usado no foro trabalhista de Buenos Aires desde 1986, faz o acompanhamento e controla os prazos, propóe agendas de audiências, sorteia os peritos. Armazenando os despachos padronizados numerados, emite e imprime os seus textos, expede notificaçôes, imprime, registra e notifica as sentenças, prepara os cálculos de liquidação. $\mathrm{Na}$ Áustria, o sistema oferece automaticamente ao juiz sugestôes apropriadas de documentos e julgamentos com formas padronizadas, antes e depois da introdução dos dados do caso, mantendo textos consistentes sobre diversos assuntos, como, por exemplo, competência” (GRECO, 2001, p. 92-93).

A constatação do comprometimento do elemento qualitativo relativamente ao tempo do processo, ou mesmo da identificação de suas raízes, não implica uma crítica ou oposição pura e simples à adoção de novas tecnologias, certamente imprescindíveis para construção de um processo que atenda aos ditames da celeridade e da efetividade. Tratase, apenas, de reconhecer os elementos envolvidos nesse trilhar e, ainda, de lograr identificar os riscos decorrentes na virtualizaçáo do processo, especialmente a fim de minorá-los. Não há um mal em si no processo eletrônico e no seu claro objetivo de diminuir o tempo entre a propositura da ação e o pronunciamento judicial, mas não se pode deixar de levar em conta as razóes econômicas e políticas que o fundamentam, e de se ponderar que a destemporalizaçáo do processo vem se dando antes de sua substancialização, reduzindo ainda mais o lugar que ocupa a analogia para interpretação e aplicação do direito nos casos concretos. E tal destemporalização da justiça, como aludem Garapon (2010, p. 53) e Jânia Maria Lopes Saldanha (2015, p. 210), pode representar o desaparecimento da própria ideia de justiça comprometida com a singularidade do caso concreto, com sua facticidade e temporalidade, como bem ensina a hermenêutica.

\section{Conclusões}

O processo eletrônico tem sido o grande protagonista dos novos tempos da atuação jurisdicional, impactando de forma concreta o meio que se utiliza para a atuaçáo do Judiciário. Há uma demanda social, política, econômica e jurídica que impele inexoravelmente o processo e a prática de atos judiciários decisórios para que se atenda aos postulados da celeridade (a razoável duração do processo) e a efetividade.

Mas o processo eletrônico tem seus próprios limites e vicissitudes. Tecnicamente, o processo eletrônico não dá conta da redução do tempo do processo em sentido estrito, pois tal medida somente se opera por dimensão normativa, qual seja, de que se tenha a prática de atos processuais típicos, legalmente chancelados, que contemple a racionalização do procedimento, a busca pela substancialização e o abandono da técnica da 
ordinarização como único elemento capaz de resolver a lide. Ademais, o sistema recursal deve ser otimizado, para que se prestigiem as decisóes de primeiro grau e para que o trilhar processual não se constitua num calvário para o litigante que tem razão.

Outros fatores importantes, que independem da adoção do modelo de processo eletrônico, também contribuem para a racionalização da prestação juridisdicional, em especial pela necessidade de aportes estruturais e de formação, evitando que se confunda o juiz com o gestor judiciário.

O processo eletrônico segue atuando de forma concreta em prol da celeridade pela atuação no tempo do meio técnico do processo, suprimindo o "tempo morto" da marcha processual e otimizando a prática de atos de caráter não decisório, fazendo com que reconhecidos gargalos do sistema processual sejam suprimidos. Enquanto o processo eletrônico atuar nesta variável haverá um ganho para a prestação jurisdicional. O risco está na tentação de transplantar o modelo de padronização oferecido pela virtualização, operando sobretudo na atuação cartorial, para o conteúdo decisório, a dimensão hermenêutica envolvida na solução de conflitos, já que não se pode ignorar a motivação econômica (redução dos custos de transação) que embala o conceito de justiça eletrônica. Processo eletrônico, sim; juiz eletrônico, não.

\section{Referências}

ALMEIDA FILHO, José Carlos de Araújo. Processo eletrônico e teoria geral do processo eletrônico: a informatização judicial no Brasil. Rio de Janeiro: Forense, 2008. ANDRADE, Andre. Acesso aos serviços de E-Gov da Justiça Brasileira. Disponível em: http://dgroups.org/file2.axd/4aca6c06-9c4a-. 45eb-9e6c- 824e3991ee81/ Acesso_aos_servicos_de_e-gov.doc. Acesso: 20 mai. 2010. ALCALÁ-ZAMORA Y CASTILLO, Niceto. Estudios de teoria general e historia del processo (1945-1972). México: Instituto de Investigaciones Jurídicas, 1974, t. 1.

ARAGÃO, Egas Dirceu Moniz. Comentários ao Código de Processo Civil. 2a ed., v. 2., Rio de Janeiro: Forense, 1976.

BAPTISTA DA SIVA, Ovídio Araújo. Epistemologia das ciências culturais. Porto Alegre: Verbo Jurídico, 2009.

BAUMAN, Zygmunt. Vigilância líquida. Rio de Janeiro: Ed. Zahar, 2014.

BECKER, L. A. Qual é o jogo do processo? Porto Alegre: Sergio Antonio Fabris Editor, 2012.

BELL, Daniel. O advento da sociedade pós-industrial. São Paulo: Hucitec, 1977.

BRASIL. Conselho Nacional de Justiça. Justiça em números 2013: ano-base 2012. Brasília: CNJ, 2013. Disponível em: http://www.cnj.jus.br/images/pesquisas- judiciarias/Publicacoes/relatorio_jn2013.pdf. Acesso em: 01 mar. 2015. 
. Conselho Nacional de Justiça. Justiça em números 2014: ano-base 2013. Brasília: CNJ, 2014. Disponível em: ftp://ftp.cnj.jus.br/Justica_em_Numeros/relatorio_jn2014.pdf. Acesso em: 01 mar. 2015.

. Conselho Nacional de Justiça. Metas 2015. Disponível em: http://www.cnj.jus. br/gestao-e-planejamento/metas/metas-2015. Acesso em: 18/02/2015. BRASIL. Lei 5.869, de 11 de janeiro de 1973. Institui o Código de Processo Civil. Diário Oficial da União, Brasília, 17 jan. 1973.

. Lei no 11.419, de 19 de dezembro de 2006. Dispóe sobre a informatização do processo judicial. Diário Oficial da União, Brasília, 20 dez. 2006.

. Análise da Gestão e Funcionamento dos Cartórios Judiciais. Ministério da Justiça - Secretaria de Reforma do Judiciário. Programa das Naçóes Unidas para o Desenvolvimento - PNUD. Brasília, 2007. Disponível em: http://www.migalhas. com.br/arquivo_artigo/art20071227.pdf. Acesso em: 07/02/2015.

. Supremo Tribunal Federal. Supremo instala relógio atômico que marca o tempo para a Justiça de todo o país. Notícias STF, 26/06/2007. Disponível em: http:// www.stf.jus.br/portal/cms/verNoticiaDetalhe.asp?idConteudo=70385\&caixaBus$\mathrm{ca}=\mathrm{N}$. Acesso em 16/02/2015.

. Tribunal Regional do Trabalho da 13a Região. Começou a era do processo sem papel no Fórum do Trabalho da Capital. Notícias do TRT13, 2009. Disponível em: http://www.trt13.jus.br/informe-se/noticias/2009/06/comeassou-aeraa-do-processo-sem-papel- no-fa3rum-do-trabalho-da-capital. Acesso em 17/02/2015.

CARNEIRO, Athos Gusmão. Cumprimento da sentença civil. Rio de Janeiro: Forense, 2007.

CARNELUTTI, Francesco. Sistema del diritto processuale civile. Pádua: Cedam, 1939, v. 3.

CARVALHO, Ricardo Motta Vaz de. O impacto do processo judicial eletrônico no direito contemporâneo. Trabalho publicado nos Anais do XIX Encontro Nacional do CONPEDI realizado em Fortaleza - CE nos dias 09, 10, 11 e 12 de Junho de 2010. Disponível em: http://www.conpedi.org.br/manaus/arquivos/anais/fortaleza/4128. pdf. Acesso em 21 fev. 2015.

COUTURE, Eduardo. Proyecto de Código de Procedimento Civil. Montevideo: s/e., 1945. CRUZ E TUCCI, José Rogério. Tempo e processo: uma análise empírica das repercussóes do tempo na fenomenologia processual (civil e penal). São Paulo: Revista dos Tribunais, 1997.

DUARTE, Ricardo Quass. O tempo inimigo no processo civil brasileiro. São Paulo: LTr, 2009. 
GAJARDONI, Fernando da Fonseca. Os reflexos do tempo no direito processual civil (anotaçóes sobre a qualidade temporal do processo civil brasileiro e europeu). Revista de Processo, vol. 153, p. 99, nov. 2007.

GARAPON, Antoine. La raison du moindre État. Le néoliberalisme el la Justice. Paris: Odile Jacob, 2010.

GRECO, Leonardo. O processo eletrônico. Direito e internet: relaçôes jurídicas na sociedade informatizada. Coordenadores Marco Aurelio Greco, Ives Gandra da Silva Martins. São Paulo: Revista dos Tribunais, 2001, p. 77-94.

HARVEY, David. Condição pós-moderna. Uma pesquisa sobre as origens da mudança cultural. Trad. Adail Ubirajara Sobral e Maria Stela Gonçalves. (The condition of postmodernity). 24a ed., São Paulo: Edições Loyola, 2013.

MACEDO, Elaine Harzheim. Sumarização do conhecimento e o devido processo legal: cisão do julgamento e cisáo do processo como limitaçáo da lide. In: Araken de Assis; Eduardo Arruda Alvim; Nelson Nery Jr; Rodrigo Mazzei; Teresa Arruda Alvim Wambier; Thereza Alvim. (Org.). Direito civil e processo: estudos em homenagem ao professor Arruda Alvim. Sáo Paulo: Editora Revista dos Tribunais, 2007, p. 10081025. Disponível em: http://www.professoraelaine.com.br/index.php/artigos/43sumarizacao-do-conhecimento-e-o- devido-processo-legal-cisao-do-julgamento-ecisao-do-processo-como-limitacao-da-lide. Acesso em: 17/02/2015.

MARINONI, Luiz Guilherme. Antecipação de tutela na reforma do processo civil. São Paulo: Malheiros, 1995.

. O custo e o tempo do processo civil brasileiro. Revista da Faculdade de Direito da Universidade Federal do Paraná, Curitiba, v. 37, 2002, p. 37-64.

. Tutela antecipatória, julgamento antecipado e execução imediata da sentença. 4a ed. São Paulo: Revista dos Tribunais, 2000.

MARRAMAO, Giacomo. Poder e secularização: as categorias do tempo. Trad. de Guilherme Alberto Gomes de Andrade. São Paulo: Editora da Universidade Estadual Paulista, 1995.

MILHORANZA, Mariângela Guerreiro. O tempo dos atos processuais: uma análise da categoria tempo no fenômeno processo. Revista de Processo, vol. 161, p. 349, jul. 2008. MORA, José Ferrater. Diccionario de filosofia abreviado, 16a ed., Buenos Aires, Sudamericana, 1986.

NUNES, Gustavo Henrique Schneider. Tempo do processo e direitos fundamentais. São Paulo: Letras Jurídicas, 2010.

ROQUE, Andre Vasconcelos; DUARTE, Francisco Carlos. As dimensóes do tempo no processo civil: tempo quantitativo, qualitativo e a duração razoável do processo. Revista de Processo, vol. 218, p. 329, abr. 2013. 
ROTTA, Maurício José Ribeiro; VIEIRA, Priscila; ROVER, Aires José; SEWALD JUNIOR, Egon. Aceleração processual e o processo judicial digital: um estudo comparativo de tempos de tramitação em Tribunais de Justiça. Revista Democracia Digital e Governo Eletrônico (ISSN 2175-9391), nº 8, p. 125-154, 2013. Disponível em: http://www.egov.ufsc.br/portal/sites/default/files/34238-45743-1-pb.pdf. Acesso em: 17/02/2015.

ROVER, Aires José. O governo eletrônico e a inclusão digital: duas faces da mesma moeda chamada democracia. In: ROVER, A. J. (ed). Inclusão digital e governo eletrônico. Zaragoza: Prensas Universitárias de Zaragoza, Lefis series 3, 2008, p. 9 - 34.

SALDANHA, Jânia Maria Lopes. Processo como analogia e aceleração processual como risco de alienação. Jurisdição, direito material e processo: os pilares da obra ovidiana e seus reflexos na aplicação do direito. Elaine Harzheim Macedo, Daniela Boito Maurmann Hidalgo (organizadoras). Porto Alegre: Livraria do Advogado Editora, 2015, p. 187-211. TARZIA, Giuseppe. O novo processo civil de cognição na Itália. Trad. Clayton Maranhão. In: Revista Ajuris, Porto Alegre, n. 65, p. 73-91, nov. 1995.

TEIXEIRA, Tarcisio. Curso de direito e processo eletrônico: doutrina, jurisprudência e prática. Sáo Paulo: Saraiva, 2013.

WATANABE, Kazuo. Da cognição no processo civil. São Paulo: RT, 1987.

ZAMUR FILHO, Jamil. Processo judicial eletrônico: alcance e efetividade sob a égide da Lei no 11.419, de 19.12.2006. Dissertação (Mestrado em Direito). São Paulo: Faculdade de Direito da Universidade de São Paulo, 2011. Disponível em: http:// www.teses.usp.br/teses/disponiveis/2/2137/tde-02052012- 105409/publico/Jamil_ Zamur_Filho_ME.pdf. Acesso em: 21/02/2015. 